\title{
Pensononowoor
}

2016, vol. 75, 167-175

http://dx.doi.org/10.12657/denbio.075.016

\author{
Mohammad Basyuni, Hiroshi Sagami, Shigeyuki Baba, \\ Hironori Iwasaki, Hirosuke Oku
}

\section{Diversity of polyisoprenoids in ten Okinawan mangroves}

\author{
Received: 7 July 2015; Accepted: 29 February 2016
}

\begin{abstract}
The distribution and occurrence of polyisoprenoids (dolichols and polyprenols) in the leaves and roots of nine true Okinawan mangroves and the leaves of one associate mangrove were analyzed using two-dimensional thin layer chromatography. In the leaves, the distribution of three types (I, II, and III) of polyprenols and dolichols were detected. (I) The predominance of dolichols over polyprenols (more than 90\%) was observed in Avicennia marina, Bruguiera gymnorrhiza, B. gymnorrhiza (yellow leaves), and Rhizophora stylosa. (II) The occurrence of both polyprenols and dolichols is observed in Excoecaria agallocha, Kandelia obovata, K. obovata (yellow leaves), Lumnitzera racemosa, Pemphis acidula, and Sonneratia alba. (III) The predominance of polyprenols over dolichols (more than 90\%) is observed in Heritiera littoralis and Hibiscus tiliaceus. However, in the roots, a type-I distribution was observed in A. marina, B. gymnorrhiza, E. agallocha, $H$. littoralis and S. alba. A type-II distribution was observed in K. obovata, L. racemosa, P. acidula, and R. stylosa with no type-III distribution. The chain-length distribution of dolichols in the leaves and roots was $\mathrm{C}_{50}-\mathrm{C}_{140}$ and $\mathrm{C}_{60}-\mathrm{C}_{120}$, respectively. A similar chain-length distribution of polyprenols of $\mathrm{C}_{45}-\mathrm{C}_{140}$ and $\mathrm{C}_{65}-\mathrm{C}_{85}$ was detected in the leaves and roots respectively. Taken together, sixteen out of twenty-one tissues indicated that dolichols are more abundant than polyprenols in both leaves and roots. The present study is the first to clarify the diversity of polyisoprenoids in both the leaves and roots of mangrove, suggesting the chemotaxonomic significance of polyisoprenoids in the mangrove tree species.
\end{abstract}

Keywords: Dolichol; leaf; Okinawan mangrove; polyprenol; root

Addresses: M. Basyuni, H. Iwasaki, H. Oku, Molecular Biotechnology Group, Tropical Biosphere Research Center, University of the Ryukyus, 1 Senbaru, Nishihara, Okinawa 903-0213, Japan, e-mail: okuhiros@ comb.u-ryukyu.ac.jp

M. Basyuni, Department of Forestry, Faculty of Forestry, University of Sumatera Utara, Jl. Tri Dharma Ujung No. 1 Medan, North Sumatera 20155, Indonesia, e-mail: m.basyuni@usu.ac.id H. Sagami, Institute of Multidisciplinary Research for Advanced Material (IMRAM), Tohoku University, 2-1-1 Katahira, Aoba-ku, Sendai 980-8577 Japan

S. Baba, International Society for Mangrove Ecosystems (ISME), Faculty of Agriculture, University of the Ryukyus, 1 Senbaru, Nishihara, Okinawa 903-0213, Japan 


\section{Introduction}

Polyisoprenoid alcohols are secondary metabolites together with sterols, ubiquinones, and plant-specific isoprenoids, which form the largest class of natural compounds. Lipid and isoprenoid composition of Okinawan mangroves and North Sumatran mangroves have been previously reported (Oku et al., 2003; Basyuni et al., 2007, 2009, 2012, 2013). Polyisoprenoid alcohols are linear five-carbon unit polymers that are present in almost all living cells. Longchain polyisoprenoids occur in various plant tissues (Swiezewska \& Danikiewicz, 2005 and cited therein). There are two types polyisoprenoids with respect to the $\alpha$-isoprene structure (Fig. 1). The first type is polyprenol (structure 1), allylic alcohols with a single double bond in each isoprenoid unit ( $\alpha$-unsaturated isoprenoid alcohols), which are characteristics of bacterial cells (Wolucka et al., 1994), plant photosynthetic tissues (Swiezewska \& Chojnacki, 1991; Kurisaki et al., 1997; Tateyama et al., 1999; Skorupinska-Tudek et al., 2003), shoots (Kurisaki et al., 1997), seeds (Kurisaki et al., 1997; Tateyama et al., 1999; Skorupinska-Tudek et al., 2003), needles (Yu et al., 2012), flowers (Tateyama et al., 1999), and cultured cells (Skorupinska-Tudek et al., 2007). The second type is dolichol (structure 2) without a double bond in the $\mathrm{OH}$-terminal isoprenoid unit ( $\alpha$-saturated isoprenoid alcohols). Dolichols occur mainly in animals (Sagami et al., 1992; Ishiguro et al., 2014), yeast cells (Grabinska \& Palamarczyk, 2002), plant roots (Tateyama et al., 1999; Skorupinska-Tudek et al., 2003), and soybean seedlings (Ishinaga et al., 1992). It is noteworthy that the composition of polyprenols in
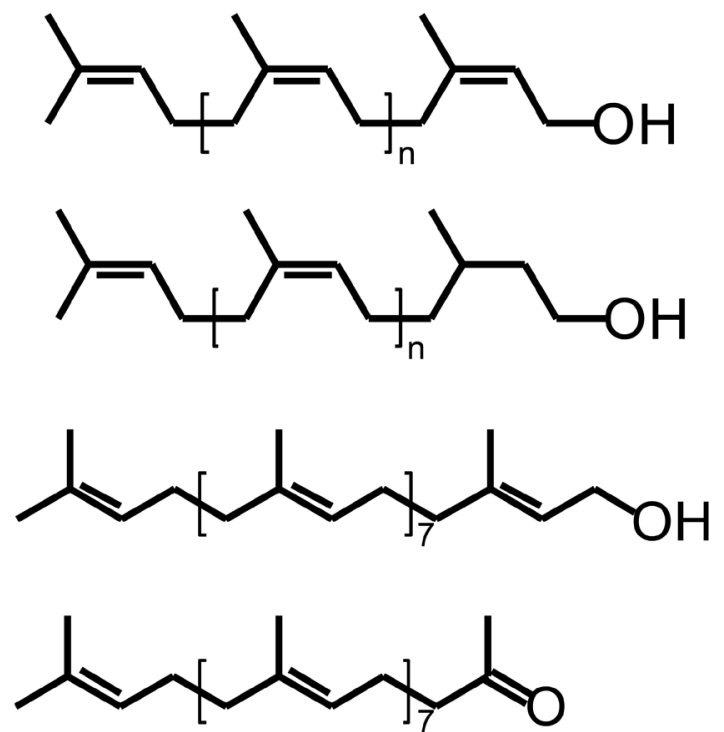

Fig. 1. Structure of polyprenol (1), dolichol (2), solanesol (3), and bombiprenone (4). $n$ shows the number of internal isoprene residues photosynthetic tissue is reproducible for certain botanical species and is considered a chemotaxonomic species-specific marker (Roslinska et al., 2002).

Despite the ubiquitous distribution of polyisoprenoids in the plant kingdom, studies on the polyisoprenoids from mangrove trees are scarce. Long-chain rubber-like polyisoprenoids occur in the leaves of the mangrove tree species Lumnitzera racemosa (Skoczylas et al., 1994). Furthermore, the contents of polyprenols and dolichols increased in a tissue or organ with senescence and upon abiotic and biotic stress (Zhang et al., 2008; Bajda et al., 2009; Baczewska et al., 2014). Despite the physiological importance of polyisoprenoids, no information on polyisoprenoid distribution in mangroves trees is available. We report here for the first time the occurrence and tissue distribution of polyprenols and dolichols together with solanesol and bombiprenone (Fig. 1, structure 3 and 4, respectively) in ten Okinawan mangroves.

\section{Materials and methods}

\section{Chemicals}

Dolichol from pig liver was obtained from Sigma-Aldrich Co. (St. Louis, Missouri, USA). A mixture of dolichol $\left(\mathrm{C}_{90}-\mathrm{C}_{105}\right)$ standard compounds was isolated from horse testicles along with a mixture of polyprenol $\left(\mathrm{C}_{90}-\mathrm{C}_{100}\right)$ from Malus sp. (Swiezewska \& Danikiewicz, 2005). The dolichols $\left(\mathrm{C}_{95}-\mathrm{C}_{110}\right)$ standards were derived from skipjack tuna livers (Ishiguro et al., 2014). The dolichol and polyprenol standards were generously provided by Dr. Ewa Swiezewska, and used to identify the polyisoprenoids that were detected in this study. The identification of the family corresponding to polyprenols or dolichols was performed in at least three experiments. Bombiprenone $\left(\mathrm{C}_{43}\right)$ as described by Toyoda et al. (1968) and Irvine et al. (1972) was purified by the silica-gel chromatography of non-saponifiable lipids of the $\mathrm{CHCl}_{3}$ / $\mathrm{CH}_{3} \mathrm{OH}(2: 1)$ extract of dry perilla leaves and its identity was confirmed by HPLC/MS to have an $m / z$ value $[\mathrm{M}+\mathrm{Na}]^{+}$of 625.53183 corresponding to $\mathrm{C}_{43} \mathrm{H}_{70} \mathrm{O}$ (bombiprenone). Solanesol $\left(\mathrm{C}_{45}\right)$ standard was prepared as described previously (Kurisaki et al., 1997). Silica gel 60 TLC plates and reversed-phase silica RP-18 HPTLC plates were purchased from Merck (Darmstadt, Germany). All of the other chemicals and solvents were of reagent grade (Sigma-Aldrich Co.).

\section{Plant materials}

The leaves and roots of nine true mangrove tree species on Iriomote Island, Okinawa Japan were collected 2-3 replicates in February: Avicennia marina 
(Forsk.) Vieh (Acanthaceae), Bruguiera gymnorrhiza (L.) Lamk. (Rhizophoraceae), Excoecaria agallocha L. (Euphorbiaceae), Heritiera littoralis Dryand. (Sterculiaceae), Kandelia obovata (S., L.) Yong (Rhizophoraceae), Lumnitzera racemosa Wild. (Combretaceae), Pemphis acidula Forst. (Lythraceae), Rhizophora stylosa Griff. (Rhizophoraceae), and Sonneratia alba J. Smith (Sonneratiaceae). The leaves of one mangrove associate, Hibiscus tiliaceus L. (Malvaceae), were also obtained from the same island in November. The age of green leaves was estimated approximately as 2-5 months whereas yellow leaves was roughly as 6-8 months. Yellow leaves still attached to branches and ready to abscise were collected randomly. Mangrove plants grew naturally with exposure to natural sun light. The average of temperature in the month of collection was $18^{\circ} \mathrm{C}$ and average humidity was $73 \%$. All of the fresh samples were kept at $-80{ }^{\circ} \mathrm{C}$ until used.

\section{Isolation of polyisoprenoid alcohols}

The procedure for the isolation of polyisoprenoids was performed as previously described (Sagami et al., 1992; Kurisaki et al., 1997). The green and yellow leaves and roots were dried at $60-75{ }^{\circ} \mathrm{C}$ for $1-2$ days. The dried tissue (5 g each) was crushed into fine powder and immersed in $30 \mathrm{ml}$ of chloroform/ methanol $(2 / 1, \mathrm{v} / \mathrm{v})$ solvent for $48 \mathrm{~h}$. The lipid extract of the leaves and roots was saponified at $65^{\circ} \mathrm{C}$ for $24 \mathrm{~h}$ in $86 \%$ ethanol containing $2 \mathrm{M} \mathrm{KOH}$. The non-saponifiable lipids of each tissue were extracted with hexane, and the organic solvent was evaporated and re-dissolved in hexane. The leaf (20-50 mg) and root (50-100 mg) extracts were applied to each TLC plate.

\section{Analysis by two-dimensional thin layer chromatography}

First-dimension TLC was carried out for $60 \mathrm{~min}$ on a silica gel glass plate $(20 \times 3 \mathrm{~cm})$ with a solvent system of toluene-ethyl acetate (9:1) as previously described (Sagami et al., 1992). The polyprenol family moved slightly faster than did the corresponding dolichol family. The longitudinal edge of the first-dimension TLC plate $1 \mathrm{~cm}$ in width and the concentration zone of a reversed-phase C-18 TLC were clamped using two magnetic bars $(4.0 \times 1.1 \times 0.8$ $\mathrm{cm}$ ) facing each gel phase. The bound TLC plate was then developed perpendicularly to the first dimension to transfer polyprenol and dolichol to the concentration zone of the reversed-phase TLC plate. The second-dimension reversed-phase C-18 silica gel TLC was performed with acetone for approximately $30 \mathrm{~min}$. The position of the separated polyisoprenoid alcohols being developed by two-dimension silica gel TLC were identified by visualization of polyisoprenoid spots on TLC chromatograms with iodine vapor prior scanning. To determine whether the family corresponds to dolichols or polyprenols, in the case of the one family that observed on two-dimensional TLC, dolichol or polyprenol reference was added to the sample line of the first-dimension TLC and developed with a solvent system as previously described. The developed chromatographic images were obtained and digitally scanned with Canon MG6100 series printer. The polyisoprenoid family was identified by the comparison of mobility on TLC with that of authentic standards of dolichol and polyprenol that were applied in the second-dimensional development.

Quantification of polyisoprenoid was done by making a standard solution using dolichol or polyprenol standard sample as internal standard for the second-dimension TLC development. A standard curve relation between dolichol or polyprenol and tentative iodine-color estimation using dolichol standard on the reverse-phase C-18 was drawn. Relative ratio of the iodine colors between dolichol analyzed on two-dimensional TLC and mangrove dolichol or polyprenol. The standard curve was then used to estimate the concentration of dolichol or polyprenol from mangrove samples. The polyprenols and dolichols that were detected on HPTLC RP-18 plates were quantified using ImageJ $1.46 \mathrm{r}$ (Schneider et al., 2012) with dolichol and polyprenol standards as references. The rubber-like compounds remaining on the top solvent front area of the first silica-gel plate without being transferred to the RP-18 plate with acetone were detected by iodine vapor.

\section{Results}

The search for long-chain polyisoprenoids from ten Okinawan mangroves was performed by two-dimensional TLC (Sagami et al., 1992) to separate polyisoprenoids into polyprenol and dolichol families with different chain lengths. Tables 1 and 2 summarize the analytical results of the occurrence and distribution of polyprenols and/or dolichols and the carbon-chain lengths of each family, respectively.

The total lipid content of mangrove leaves (Table 1) ranged from 34-264 $\mathrm{mg} \mathrm{g}^{-1}$ dry weight with an average of $112 \mathrm{mg} \mathrm{g}^{-1}$ dry weight and the lowest and the highest in $P$. acidula, and $K$. obovata, respectively. In contrast, the total lipid content of mangrove roots ranged from $2-212 \mathrm{mg} \mathrm{g}^{-1}$ dry weight, with an average of $44 \mathrm{mg} \mathrm{g}^{-1}$ dry weight and, the lowest in $H$. littoralis and the highest in A. marina, respectively. The quantity of polyisoprenoids was the highest in $H$. tiliaceus leaves (13.9 $\mathrm{mg} \mathrm{g}^{-1}$ dry weight). The low- 
Table 1. Occurrence and distribution of polyprenols and dolichols in ten Okinawan mangroves

\begin{tabular}{|c|c|c|c|c|c|c|c|c|c|c|}
\hline \multirow[b]{2}{*}{ Species } & \multirow[b]{2}{*}{ Tissue } & \multirow{2}{*}{$\begin{array}{l}\text { Total lipids } \\
\text { (mg/g dw) }\end{array}$} & \multirow{2}{*}{$\begin{array}{l}\text { Polyisoprenoids } \\
\quad(\mathrm{mg} / \mathrm{g} \mathrm{dw})\end{array}$} & \multirow{2}{*}{$\begin{array}{l}\text { Polyprenols } \\
(\mathrm{mg} / \mathrm{g})\end{array}$} & \multirow[b]{2}{*}{$\begin{array}{l}\text { Dolichols } \\
\text { (mg/g) }\end{array}$} & \multicolumn{3}{|c|}{$\%$ in total lipid } & \multicolumn{2}{|c|}{$\%$ in polyisoprenoid } \\
\hline & & & & & & $\begin{array}{l}\text { Polyiso- } \\
\text { prenoid }\end{array}$ & $\begin{array}{l}\text { Poly- } \\
\text { prenol }\end{array}$ & $\begin{array}{l}\text { Doli- } \\
\text { chol }\end{array}$ & $\begin{array}{c}\text { Poly- } \\
\text { prenol }\end{array}$ & $\begin{array}{c}\text { Doli- } \\
\text { chol }\end{array}$ \\
\hline A. marina & leaves & $108 \pm 8.4$ & 3,3 & 0,1 & 3,2 & 3,1 & 0,1 & 3,0 & 4,2 & 95,8 \\
\hline \multirow[t]{2}{*}{ B. gymnorrhiza } & leaves & $154 \pm 15.5$ & 3,7 & nd & 3,7 & 2,4 & nd & 2,4 & nd & 100,0 \\
\hline & yellow leaves & $116 \pm 9.2$ & 4,0 & 0,4 & 3,6 & 3,4 & 0,3 & 3,1 & 9,1 & 90,9 \\
\hline E. agallocha & leaves & $72 \pm 9.5$ & 2,4 & 1,5 & 0,9 & 3,4 & 2,1 & 1,3 & 62,3 & 37,7 \\
\hline H. littoralis & leaves & $86 \pm 6.0$ & 9,2 & 9,2 & nd & 10,7 & 10,7 & nd & 100,0 & nd \\
\hline H. tiliaceus & leaves & $100 \pm 5.7$ & 13,9 & 13,9 & nd & 13,9 & 13,9 & nd & 100,0 & nd \\
\hline \multirow[t]{2}{*}{ K. obovata } & leaves & $264 \pm 18.0$ & 5,9 & 1,4 & 4,5 & 2,2 & 0,5 & 1,7 & 23,7 & 76,3 \\
\hline & yellow leaves & $92 \pm 2.8$ & 12,9 & 7,4 & 5,5 & 14,0 & 8,0 & 6,0 & 57,1 & 42,9 \\
\hline L. racemosa & leaves & $120 \pm 12.1$ & 6,7 & 3,0 & 3,7 & 5,6 & 2,5 & 3,1 & 44,8 & 55,2 \\
\hline P. acidula & leaves & $34 \pm 7.1$ & 1,5 & 0,7 & 0,8 & 4,4 & 2,2 & 2,2 & 49,3 & 50,7 \\
\hline R.stylosa & leaves & $136 \pm 7.8$ & 6,1 & 0,4 & 5,7 & 4,5 & 0,3 & 4,2 & 6,3 & 93,7 \\
\hline S. alba & leaves & $60 \pm 17.0$ & 8,6 & 5,0 & 3,6 & 14,4 & 8,3 & 6,1 & 57,8 & 42,2 \\
\hline A. marina & roots & $212 \pm 12.7$ & 2,3 & nd & 2,3 & 1,1 & nd & 1,1 & nd & 100,0 \\
\hline B. gymnorrhiza & roots & $14 \pm 2.1$ & 0,8 & 0,1 & 0,7 & 5,5 & 0,4 & 5,1 & 6,6 & 93,4 \\
\hline E. agallocha & roots & $14 \pm 1.4$ & 0,8 & nd & 0,8 & 5,6 & nd & 5,6 & nd & 100,0 \\
\hline H. Littoralis & roots & $2 \pm 1.4$ & 0,7 & nd & 0,7 & 34,0 & nd & 34,0 & nd & 100,0 \\
\hline K. obovata & roots & $54 \pm 4.9$ & 1,2 & 0,3 & 0,9 & 2,2 & 0,6 & 1,6 & 25,4 & 74,6 \\
\hline L. racemosa & roots & $6 \pm 2.1$ & 0,8 & 0,2 & 0,6 & 13,3 & 3,3 & 10,0 & 25,0 & 75,0 \\
\hline P. acidula & roots & $26 \pm 2.8$ & 0,9 & 0,1 & 0,8 & 3,5 & 0,5 & 3,0 & 15,2 & 84,8 \\
\hline R.stylosa & roots & $32 \pm 1.0$ & 1,0 & 0,4 & 0,6 & 3,1 & 1,2 & 1,9 & 38,8 & 61,2 \\
\hline S. alba & roots & $36 \pm 1.4$ & 1,0 & nd & 1,0 & 2,7 & nd & 2,7 & nd & 100,0 \\
\hline
\end{tabular}

nd $=$ not detected. Total lipids are represented as the mean \pm SD $(n=2-3)$.
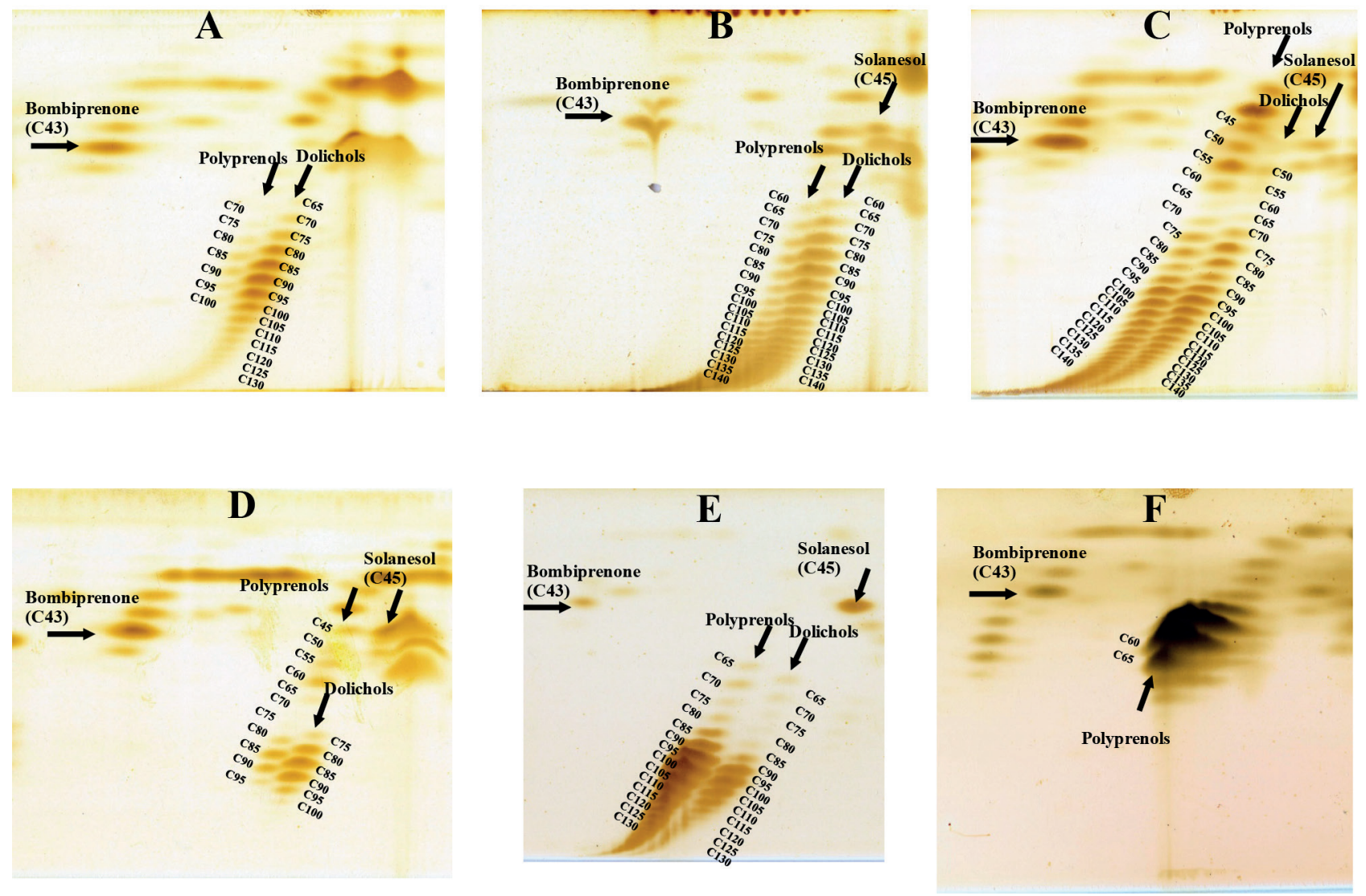

Fig. 2. Two-plate TLC of polyisoprenoids from A. marina leaves (A), L. racemosa leaves (B), P. acidula leaves (C), yellow leaves of $K$. obovata (D), S. alba leaves (E), and $H$. tiliaceus leaves (F). The carbon number refers to the carbon-chain length of polyisoprenoid alcohols 


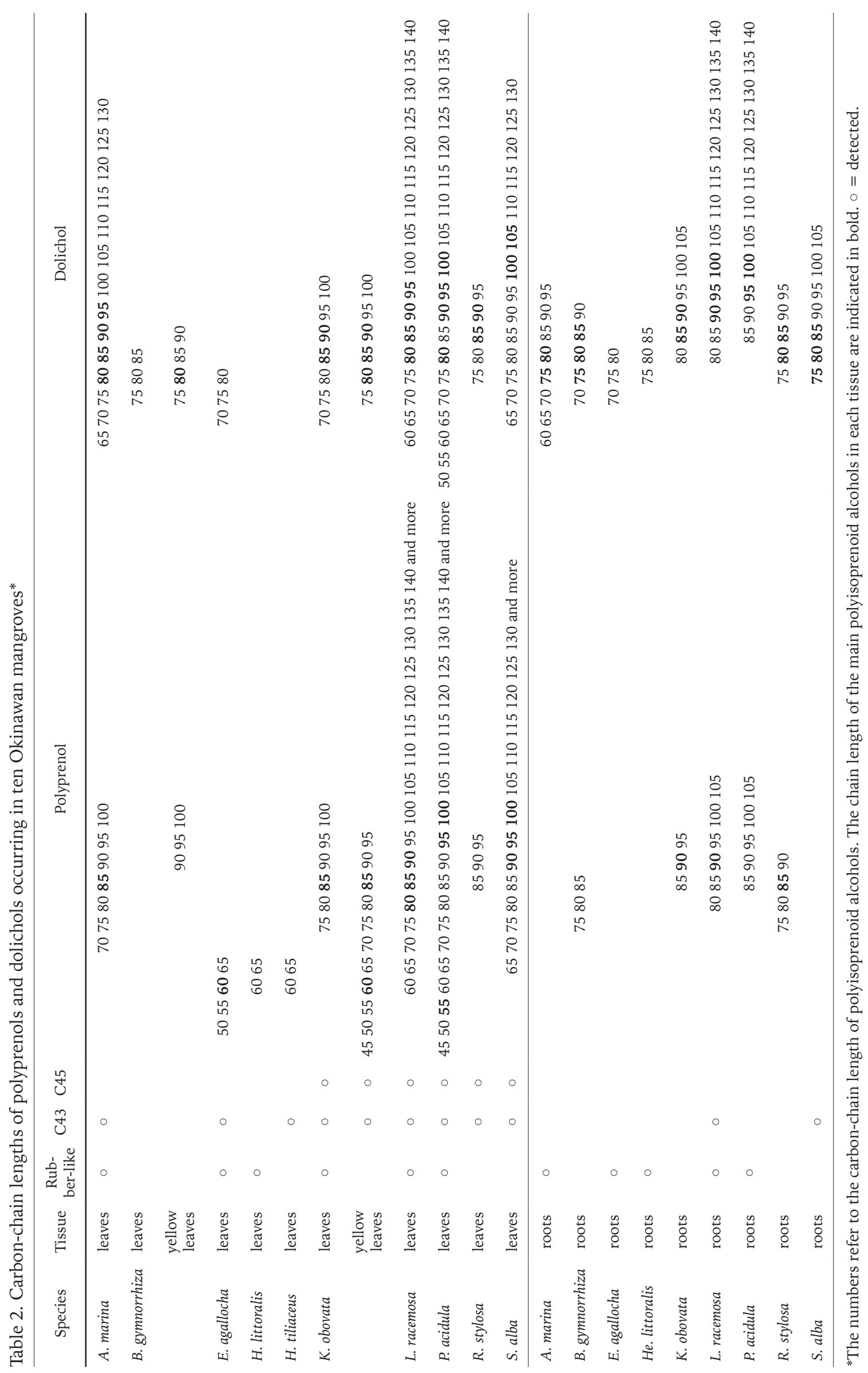


est content of polyisoprenoids was in the roots $(0.7$ $\mathrm{mg} \mathrm{g}^{-1}$ dry weight) of $H$. littoralis.

The distribution of polyprenols and dolichols in the leave's polyisoprenoids can be classified into three types (I, II, and III). In type -I, the predominance of dolichols over polyprenols (more than 90\%) was observed in A. marina, B. gymnorrhiza, B. gymnorrhiza (yellow leaves), and $R$. stylosa. In A. marina and $R$. stylosa, a trace amount of polyprenols with chain lengths similar to those of dolichols was detected as shown in Fig. 2A and Supplementary Fig. 1F, respectively, but in B. gymnorrhiza leaves and yellow leaves (Supplementary Fig. $1 \mathrm{~A}$ and $1 \mathrm{~B}$, respectively), polyprenols with chain lengths similar to those of dolichols were not detected, although polyprenols that were much longer than dolichols were detected in B. gymnorrhiza (Supplementary Fig. 1B and Table $2)$. In type -II, the occurrence of both polyprenols and dolichols was observed in E. agallocha, K. obovata, $K$. obovata (yellow leaves), L. racemosa, P. acidula, and $S$. alba (Table 1). In E. agallocha, the chain lengths differed between polyprenols and dolichols, as shown in Supplementary Fig. 1C and Table 2. In both K. obovata and $K$. obovata (yellow leaves), polyprenols with a chain length similar to that of dolichols were detected, as shown in Supplementary Fig. 1E and Fig. $2 \mathrm{D}$, respectively, and another polyprenol family was also detected especially in yellow leaves. In L. race-
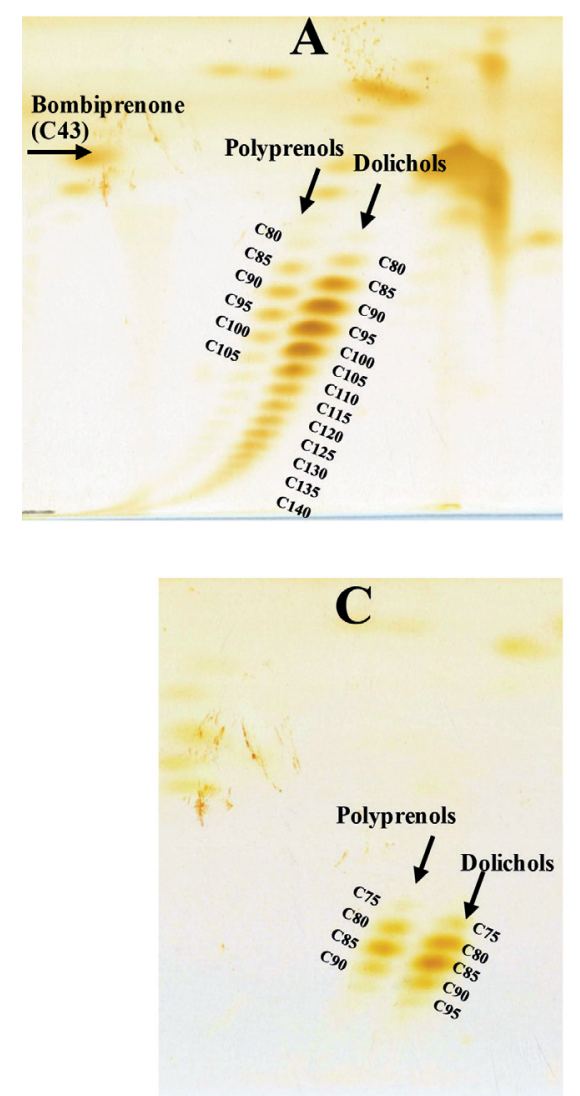

mosa, $P$. acidula, and $S$. alba, polyprenols much longer than dolichols in chain length were also detected, as shown in Fig. 2B, Fig. 2C, and Fig. 2E, respectively (See Table 2). In type -III, the predominance of polyprenols over dolichols (more than 90\%) was observed in $H$. littoralis and $H$. tiliaceus (mangrove associate). In these cases, the chain length of the detected polyprenols were $\mathrm{C}_{60}$ and $\mathrm{C}_{65}$, as shown in Supplementary Fig. 1D and Fig. 2F, respectively, and in Table 2. Similar shorter-chain polyprenols were also detected in E. agallocha leaves, P. acidula leaves and yellow leaves of K. obovata (Supplementary Fig. 1C, Fig. 2C, and Fig. 2D, respectively and Table 2).

However, regarding the root's polyisoprenoids, the predominance of dolichols over polyprenols was observed in A. marina, B. gymnorrhiza, E. agallocha, $H$. littoralis, and S. alba, similar to that found in the type-I leaves. In A. marina, E. agallocha, $H$. littoralis, and $S$. alba, dolichols with no polyprenols were observed as shown in Supplementary Figs. 2A, 2C, 2D, and 3C, respectively, although a trace amount of polyprenols was detected in B. gymnorrhiza (Supplementary Fig. 2B). A significant amount of polyprenols together with dolichols were observed in the roots of $\mathrm{K}$. obovata, $L$. racemosa, $P$. acidula, and $R$. stylosa, similar to type-II leaves. Both polyprenols and dolichols were detected in K. obovata (Supplementary Fig. 2E) and in R. stylosa (Fig. 3C). In L. racemosa (Fig. 3A) and P.
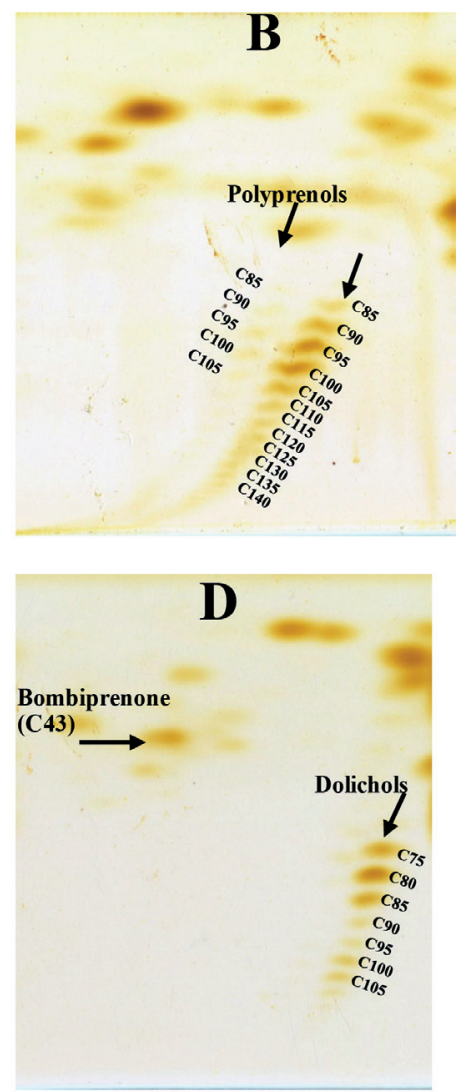

Fig. 3. Two-plate TLC of polyisoprenoids from L. racemosa roots (A), P. acidula roots (B), R. stylosa roots (C), and S. alba roots (D). The carbon number refers to the carbon-chain length of polyisoprenoid alcohols 
acidula (Fig. 3B), longer dolichols were also detected, similar to those in their leaves. The distribution of the predominance of polyprenols over dolichols, similar to type-III leaves, was not observed in any roots, though analytical studies were not performed for $H$. tiliaceus roots.

\section{Discussion}

Analysis of polyisoprenoid in leaves of mangrove plants the major polyisoprenoid alcohols are not polyprenols but dolichols. As shown in Table 1, dolichols were found in all tissues except for the leaves of $H$. littoralis and $\mathrm{H}$. tiliaceus. It has been suggested by Tateyama et al. (1999) that the chain length of dolichols varied from tissue to tissue, even in the same species and appeared to form distinct families with dominating molecule species. Polyprenols also occurred as one or two polyprenols families, depending on the plants and tissues. Two polyprenols families were detected in yellow leaves of $K$. obovata (Fig. 2D) and the leaves of L. racemosa and P. acidula (Fig. 2B and 2C, respectively). The major molecules in each family varied with mangrove species: $\mathrm{C}_{60}$ and $\mathrm{C}_{85}$ for $\mathrm{K}$. obovata; $\mathrm{C}_{55}$ and $\mathrm{C}_{95}-\mathrm{C}_{100}$ for P. acidula; and $\mathrm{C}_{80}-\mathrm{C}_{90}$ and $\mathrm{C}_{120}$ for $L$. racemosa (Table 2 ). The longer chain polyprenol family was also found in L. racemosa leaves (Fig. 2B), P. acidula leaves (Fig. 2C), and S. alba leaves (Fig. 2E). In contrast to this observation, dolichols occurred as one dolichol family with a dominating length of $\mathrm{C}_{80}-$ $\mathrm{C}_{95}$ in $L$. racemosa leaves, $\mathrm{C}_{75}-\mathrm{C}_{80}$ and $\mathrm{C}_{90}-\mathrm{C}_{100}$ in $P$. acidula leaves and $\mathrm{C}_{95}-\mathrm{C}_{105}$ in $S$. alba leaves depending on the mangrove species and tissue (Table 2). These results therefore indicate that the biosynthetic pathway from polyprenols to dolichols may be regulated by polyprenol reductase with strict substrate specificity to chain-length in mangrove plants.

The accumulation of polyprenols with age was noted with yellow leaves of $K$. obovata with a 5 -fold increase (Table 1). Polyprenols and dolichols in yellow leaves of $K$. obovata similarly increased with age, while yellow leaves of B. gymnorrhiza were opposite in that dolichols slightly decreased with age. The increase in polyprenols with age has been reported in old ginkgo leaves (Tateyama et al., 1999), old rubber leaves (Tateyama et al., 1999) and senescing leaves (Swiezewska et al., 1994). The pattern of polyprenyl esters was more complex in old L. racemosa leaves, with polyprenyl esters in the range of prenol-20 to prenol-80 forming 2-3 subgroups (Skoczylas et al., 1994). However the results of the previous analysis (Skoczylas et al., 1994) is slightly different, namely dolichols have not detected in leaf extract. This discrepancy with our present study might it result from the differences in the age of the leaves or environmental conditions. These observations suggest that the biosynthetic pathways of shorter polyprenols, medium polyprenols, longer polyprenols and dolichols are differently regulated in the plant kingdom, including mangrove plants.

The occurrence of longer dolichols in the roots of L. racemosa and P. acidula (Fig. 3A and 3B, respectively) appeared to be at least partly correlated with a cross-section of the main roots of seven Okinawan mangroves, divided into two types of main roots (Oku et al., 2003). One structure is well-developed aerenchyma in the cortex (Tomlinson, 1986), as exemplified by A. marina, B. gymnorrhiza, K. obovata, $R$. stylosa, and $S$. alba. These species were comprised of shorter to medium dolichols $\left(\mathrm{C}_{60-105}\right)$, including $E$. agallocha and $\mathrm{H}$. littoralis in this study. Another type showing a broad lacunose cortex, no trichosclereids and containing longer dolichols $\left(\mathrm{C}_{80-140}\right)$ developed (Tomlinson, 1986) in L. racemosa and P. acidula (Oku et al., 2003).

Dolichols were predominated in sixteen out of twenty-one mangrove tissues, including the leaves and roots (Table 1 and 2). Therefore, the occurrence of larger amounts of dolichols even in the leaves of mangrove plants, implies that polyprenols play no important role in several mangrove leaves, although the function of polyprenols in the plant world remains unclear. Finally, the present study importantly revealed that much longer chain dolichols $\left(\mathrm{C}_{130-140}\right)$ occur in L. racemosa and P. acidula leaves and roots. In the future, it will be very important to understand whether those longer dolichols are able to function as sugar-carrier lipids in the biosynthesis of $\mathrm{N}$-glycoproteins, together with the understanding of whether polyprenol reductases in $L$. racemosa and $P$. acidula, which catalyze the conversion of polyprenol to dolichol corresponding to the SRD5A-3 protein in animals (Cantagrel et al., 2010), differ from those of other mangrove plants in reduction activity.

\section{Conclusions}

In the plant world (especially in leaves), polyprenols rather than dolichols are usually abundantly detected (Swiezewska et al., 1994; Tateyama et al., 1999; Swiezewska \& Danikiewicz, 2005). In addition, in the animal world (livers), dolichols were predominant, and few polyprenols occurred (Chojnacki \& Dallner, 1988; Daniels \& Hemming, 1990; Sagami et al., 1992). The distribution of dolichols and polyprenols found in mangrove plants varies depending on each tissue. Further experiments are necessary to clarify the physiological significance of polyisoprenoid alcohols under environmental stresses such as salinity and shading as well as the molecular cloning of the polyisoprenoid biosynthesis gene in mangrove plants. 


\section{Acknowledgements}

The authors are grateful to Dr. Ewa Swiezewska (Polish Academy of Sciences) for the mixture dolichol and polyprenol standards. A part of this study was supported by a Grant-in Aid from the Saudi Aramco Okinawa Research Fund for Mangrove Ecosystem Conservation (SAOREFMEC to SB) and a Competence Grant (No. 120/SP2H/PL/Dit.Litabmas/ II/2015 to MB) from the Directorate for Research and Community Service, Ministry of Research, Technology and Higher Education, Republic of Indonesia.

\section{References}

Baczewska AH, Dmuchowski W, Jozwiak A, Gozdowski D, Brągoszewska P, Dąbrowski P \& Swiezewska E (2014) Effect of salt stress on prenol lipids in the leaves of Tilia 'Euchlora'. Dendrobiology 72: 177-186. doi:10.12657/denbio.072.015.

Bajda A, Konopka-Postupolska D, Krzymowska M, Hennig J, Skorupinska-Tudek K, Surmacz L, Wójcik J, Matysiak Z, Chojnacki T, Skorzynska-Polit E, Drazkiewicz M, Patrzylas P, Tomaszewska M, Kania M, Swist M, Danikiewiczc W, Piotrowska W \& Swiezewska E (2009) Role of polyisoprenoids in tobacco resistance against biotic stresses. Physiologia Plantarum 135: 351-364. doi:10.1111/ j.1399-3054.2009.01204.x.

Basyuni M, Oku H, Baba S, Takara K \& Iwasaki H (2007) Isoprenoids of Okinawan mangroves as lipid input into estuarine ecosystem. Journal of Oceanography 63: 601-608. doi:10.1007/s10872007-0053-2.

Basyuni M, Baba S, Inafuku M, Iwasaki H, Kinjo K \& Oku H (2009) Expression of terpenoid synthase mRNA and terpenoid content in salt stressed mangrove. Journal of Plant Physiology 166: 17861800. doi:10.1016/j.jplph.2009.05.008.

Basyuni M, Putri LAP, Nurainun H, Julayha \& Oku H (2012) Non-saponifiable lipid composition of four salt-secretor and non-secretor mangrove species from North Sumatra, Indonesia. Makara Journal of Science 16: 89-94. doi:10.7454/mss. v16i2.1402.

Basyuni M, Putri LAP \& Oku H (2013) Phytomedicinal investigation from six mangrove tree species, North Sumatra, Indonesia. Ilmu Kelautan: Indonesian Journal of Marine Sciences 18: 157-164.

Chojnacki T \& Dallner G (1988) The biological role of dolichol. Biochemical Journal 251: 1-9.

Cantagrel V, Lefeber DJ, Ng BG, Guan Z, Silhavy JL, Bielas SL, Lehle L, Hombauer H, Adamowicz M, Swiezewska E, De Brouwer AP, Blümel P, Sykut-Cegielska J, Houliston S, Swistun D, Ali
BR, Dobyns WB, Babovic-Vuksanovic D, van Bokhoven H, Wevers RA, Raetz CR, Freeze HH, Morava E, Al-Gazali L \& Gleeson JG (2010) SRD5A3 is required for converting polyprenol to dolichol and is mutated in a congenital glycosylation disorder. Cell 142: 203-217. doi:10.1016/j. cell.2010.06.001.

Daniels I \& Hemming FW (1990) Changes in murine tissue concentrations of dolichol and dolichol derivatives associated with age. Lipids 25: 586-593. doi:10.1007/BF02536006.

Grabinska K \& Palamarczyk G (2002) Dolichol biosynthesis in the yeast Saccharomyces cerevisiae: an insight into the regulatory role of farnesyl diphosphate synthase. FEMS Yeast Research 2: 259-265. doi:10.1111/j.1567-1364.2002.tb00093.x.

Irvine WJ, Woollen BH \& Jones DH (1972) Bombiprenone from Nicotiana tabacum. Phytochemistry 11: 467-469.

Ishiguro T, Morita-Fujimira Y, Shidoji Y \& Sagami H (2014) Dolichol biosynthesis: The occurrence of epoxy dolichol in skipjack tuna liver. Biochemical and Biophysical Research Communications 453: 277-281. doi:10.1016/j.bbrc.2014.05.079.

Ishinaga M, Yamauchi T, Egusa K \& Mukai K (1992) Changes of dolichol and dolichyl fatty ester contents during development of soybean seedlings. Bioscience, Biotechnology, and Biochemistry 56: 961-962.

Kurisaki A, Sagami H \& Ogura K (1997) Distribution of polyprenols and dolichols in soybean plant. Phytochemistry 44: 45-50. doi:10.1016/S00319422(96)00400-1.

Oku H, Baba S, Koga H, Takara K \& Iwasaki H (2003) Lipid composition of mangroves and its relevance to salt tolerance. Journal of Plant Research 116: 37-45. doi:10.1007/s10265-002-0069-z.

Roslinska M, Walinska K, Swiezewska E \& Chojnacki $\mathrm{T}$ (2002) Plant long-chain polyprenols as chemotaxonomic markers. Dendrobiology 47: 41-50.

Sagami H, Kurisaki A, Ogura K \& Chojnacki T (1992) Separation of dolichol from dehydrodolichol by a simple two-plate thin layer chromatography. Journal of Lipid Research 33: 1857-1862.

Schneider CA, Rasband WS \& Eliceiri KW (2012) NIH image to Image $: 25$ years of image analysis. Nature Methods 9: 671-675.

Skoczylas E, Swiezewska E, Chojnacki T \& Tanaka Y (1994) Long-chain rubber-like polyisoprenoid alcohols in leaves of Lumnitzera racemosa. Plant Physiology and Biochemistry 32: 825-829.

Skorupinska-Tudek K, Bienkowski T, Olszowska O, Furmanowa M, Chojnacki T, Danikiewicz W \& Swiezewska E (2003) Divergent pattern of polyisoprenoid alcohols in the tissues of Coluria geoides: a new electrospray ionization MS ap- 
proach. Lipids 38: 981-990. doi:10.1007/s11745003-1152-3.

Skorupinska-Tudek K, Pytelewska A, Zelman-Femiak M, Mikoszewski J, Olszowska O, Gajdzis-Kuls D, Urbanska N, Syklowska-Baranek K, Hertel J, Chojnacki T \& Swiezewska E (2007) In vitro plant tissue cultures accumulate polyisoprenoid alcohols. Acta Biochimica Polonica 54: 847-852.

Swiezewska E \& Chojnacki T (1991) Long-chain polyprenols from Potentilla aurea. Phytochemistry 30: 267-270. doi:10.1016/0031-9422(91)84135-F.

Swiezewska E, Sasak W, Mankowski T, Jankowski W, Vogtman T, Krajewska I, Hertel J, Skoczylas E \& Chojnacki T (1994) The search for plant polyprenols. Acta Biochimica Polonica 41: 221-260.

Swiezewska E \& Danikiewicz W (2005) Polyisoprenoids: Structure, biosynthesis and function. Progress in Lipid Research 44: 235-258. doi:10.1016/j.plipres.2005.05.002.

Tateyama S, Wititsuwannakul R, Wititsuwannakul D, Sagami H \& Ogura K (1999) Dolichols of rubber plant, ginkgo and pine. Phytochemistry 51: 11-15. doi:10.1016/S0031-9422(98)00581-0.
Tomlinson PB (1986) The botany of mangroves. 1st ed. Cambridge University Press, London.

Toyoda M, Fukawa H \& Shimizu T (1968) Isolation of new poliisoprenyl ketone from silkworm feces. Tetrahedron Letters 9: 3837-3840.

Wolucka BA, McNeil MR, de Hoffmann E, Chojnacki T \& Brennan PJ (1994) Recognition of the lipid intermediate for arabinogalactan/arabinomannan biosynthesis and its relation to the mode of action of ethambutol on mycobacteria. Journal of Biological Chemistry 269: 23328-23335.

Yu J, Wang Y, Qian H, Zhao Y, Liu B \& Fu C (2012) Polyprenols from the needles of Taxus chinensis var. mairei. Fitoterapia 83: 831-837. doi:10.1016/j.fitote.2012.01.007.

Zhang H, Ohyama K, Boudet J, Chen Z, Yang J, Zhang M, Muranaka T, Maurel C, Zhu JK \& Gong Z (2008) Dolichol biosynthesis and its effects on the unfolded protein response and abiotic stress resistance in Arabidopsis. Plant Cell 20:18791898. doi:10.1105/tpc.108.061150. 